\title{
Deslocamento miscível de cátions básicos provenientes da água residuária de mandioca em colunas de solo ${ }^{1}$
}

\begin{abstract}
Ralini F. de Melo ${ }^{2}$, Paulo A. Ferreira ${ }^{3}$, Antônio T. de Matos ${ }^{3}$, Hugo A. Ruiz ${ }^{3}$ \& Lindomário B. de Oliveira ${ }^{4}$
\section{RESUMO}

Objetivou-se, com este estudo, determinar os fatores de retardamento e os coeficientes de dispersão-difusão dos íons potássio, sódio, cálcio e magnésio, presentes na água residuária de fecularias ou manipueira, e simular as concentrações residentes em colunas de solos de $160 \mathrm{~cm}$, pelo período de $5 \mathrm{~h}$. Os ensaios foram realizados em laboratório utilizando-se colunas de percolação preenchidas com amostras de Neossolo Quartzarênico órtico espódico (RQo), Latossolo Amarelo distrófico típico (LAd) e Latossolo Vermelho Amarelo distrófico típico (LVAd). A concentração dos íons no efluente foram analisados empregando-se a metodologia de deslocamento de fluidos miscíveis. Os valores mais elevados dos fatores de retardamento ocorreram no LVAd, indicando maior retenção dos íons potássio, sódio, cálcio e magnésio nesse solo. Os valores dos coeficientes dispersivos-difusivos decresceram no sentido do RQo para o LVAd, sendo que o maior valor ocorreu no RQo para o íon potássio, e o menor no LVAd, para o íon cálcio. A simulação para um período de aplicação da manipueira de 5 h, mostrou pequeno avanço dos íons na coluna do LVAd, em comparação com RQo e LAd alertando, assim, para os perigos de contaminação de águas subterrâneas ao se aplicar a manipueira nesses solos.
\end{abstract}

Palavras-chave: água residuária de fecularia, fator de retardamento, coeficiente de dispersão-difusão, concentração residente

\section{Miscible displacement of basic cations from cassava processing wastewater in soil columns}

\begin{abstract}
This study aimed to determine the retardation factors and the diffusion-dispersion coefficients of the potassium, sodium, calcium and magnesium ions found in the cassava wastewater, as well as to simulate the resident concentrations in soil columns with $160 \mathrm{~cm}$ over a five-hours period. The trials were accomplished under laboratory conditions, by using percolation columns fulfilled with materials from the spodic ortic Quartzarenic Neosol (RQo), typical distrophic Yellow Latosol (LAd) and typical distrophic Yellow Red Latosol (LVAd). The data of the ion concentrations in effluent were analyzed, by using the miscible fluid displacement methodology. The highest values of the retardation factors occurred in the LVAd soil, relative to LAd and RQo soils, pointing out a higher retention of the potassium, sodium, calcium and magnesium ions in the LVAd soil. The values of the diffusive-dispersive coefficients decreased from LVAd toward the RQo soil, whereas the highest value occurred in the RQo soil for the potassium ion and the lowest in the LVAd soil for calcium ion. The simulation of the cassava wastewater application over a five-hours period showed little advance of these ions in the LVAd soil column, comparative to the advance occurred in the RQo and LAd soils, therefore warning about the dangers of the underground water contamination, when applying the cassava wastewater on these two soils.
\end{abstract}

Key words: wastewater, retardation factor, dispersive-diffusive coefficient, resident concentration

1 Parte da Dissertação de Mestrado da primeira autora, apresentada à Universidade Federal de Viçosa

${ }^{2}$ Doutoranda em Agronomia, ESALQ/USP. Av. Pádua Dias, 11, CEP 13418-900, Piracicaba, SP. Fone: (19) 3429 4217, ramal 263. E-mail: fmralini@yahoo.com.br

${ }_{3}^{3}$ DEA e DPS/UFV. Av. PH Rolfs, s/n, CEP 36570-000, Viçosa, MG. Fone: (31) 3899 1911. E-mail: pafonso@ufv.br

${ }^{4}$ MAPA, Esplanada dos Ministérios. Bloco D, Anexo B, sala 216, CEP 70043-900, Brasília, DF. Fone: (61) 218 2040. E-mail: Ibdeoliveira@yahoo.com.br 


\section{INTRODUÇÃO}

A agricultura moderna fundamenta-se no uso de diversos tipos de insumo, tais como: inseticidas, herbicidas, fungicidas, fertilizantes e irrigação, dentre outros; entretanto, para sua sustentabilidade é essencial que a utilização desses insumos não comprometa a qualidade do meio ambiente (Matos et al., 2003).

A preocupação com os impactos ambientais cresce à medida que os resíduos agroindustriais são utilizados na agricultura, como forma de compatibilizar sua destinação final com as necessidades de fertilizantes das culturas (Matos, 1995). Dentre as diversas águas residuárias aplicadas ao solo, tem-se a manipueira, que é oriunda das indústrias de fecularias e casas de farinha de mandioca.

A manipueira apresenta atributos favoráveis, do ponto de vista do uso agrícola como fonte de nutrientes às plantas; todavia, pode causar danos ao solo e às plantas, caso seja utilizada sem critérios técnicos ao aplicá-la. Por ser uma água rica em potássio, apresentando cerca de $580 \mathrm{mg} \mathrm{L}^{-1}$, um excesso deste íon no solo tanto pode afetá-lo negativamente como às plantas, caso provoque a dispersão das argilas e/ou desequilíbrio nutricional.

Outra preocupação se refere à lixiviação dos íons pelas águas de chuva e irrigação, podendo contaminar tanto corpos de águas superficiais quanto subterrâneas (Matos et al., 1995; Ponte, 1999; Vilas Boas et al., 2001).

No Brasil, esta preocupação se reveste de especial importância, visto que a utilização de resíduos industriais na agricultura tem sido feita, em muitos casos, de modo indiscriminado. A recomendação para o descarte de resíduos no meio ambiente deve ser precedida de estudos detalhados dos efeitos decorrentes da adsorção de íons pela fração coloidal do solo e da mobilidade desses íons no perfil (Alcântara \& Camargo, 2001).

A mobilidade dos íons no solo pode ser avaliada por meio de técnicas baseadas em deslocamento de fluidos miscíveis e recursos computacionais. Modelos físico-matemáticos resultantes de soluções de equação diferencial de transporte de solutos no solo, quando ajustados a dados experimentais oriundos de ensaios de lixiviação e eluição de íons em colunas de solo em laboratório ou no campo, por meio de programas computacionais, constituem-se em ferramentas poderosas por possibilitarem a caracterização da mobilidade dos solutos no solo com base na dispersão, difusão e retardamento dos solutos em relação ao avanço da interface entre o líquido deslocador e o deslocado (Ferreira, 2003).

Objetivou-se, neste trabalho, determinar os fatores de retardamento, coeficientes dispersivos-difusivos e as concentrações residentes dos íons cálcio, magnésio, sódio e potássio, e simular as concentrações residentes dos solutos contidos na água residuária do processamento de mandioca, em colunas de percolação preenchidas com material de três solos.

\section{MATERIAL E MÉTODOS}

Coleta e caracterização física e química da água residuária

Coletaram-se amostras de água residuária por ocasião do processamento da mandioca para fabricação de polvilho, em abril de 2003, no município de Consolação, região sul do estado de Minas Gerais.

A caracterização física e química da água residuária foi realizada no Laboratório de Qualidade da Água do Departamento de Engenharia Agrícola da UFV. As análises químicas consistiram na quantificação de cálcio e magnésio, por espectrofotometria de absorção atômica, potássio e sódio, por fotometria de chama (Rump \& Krist, 1992). Nas análises físicas determinaram-se as concentrações de sólidos sedimentáveis (SP), em cone de Imhoff, e sólidos totais (ST), após secagem em estufa a $110{ }^{\circ} \mathrm{C}$ por $24 \mathrm{~h}$ (APHA, 1995).

As amostras de Neossolo Quartzarênico órtico espódico (RQo), Latossolo Amarelo Distrófico típico (LAd) e Latossolo Vermelho Amarelo Distrófico típico (LVAd) foram coletadas na camada superficial $(0-20 \mathrm{~cm})$. Elas foram secadas ao ar e, após passados em peneira de malha de $2 \mathrm{~mm}$, analisados química e fisicamente (Tabela 1), no Laboratório de Água e Solo do Departamento de Engenharia Agrícola e Física do Solo do Departamento de Solos, da UFV.

Tabela 1. Classificação e localidade onde os solos foram amostrados no estado de Minas Gerais

\begin{tabular}{|c|c|c|c|}
\hline Identificação ${ }^{1}$ & Classe textural & Localidade & Coordenadas \\
\hline RQo & Areia & $\begin{array}{l}\text { Itutinga - Usina Hidrelétrica } \\
\text { de Furnas }\end{array}$ & $\begin{array}{l}21^{0} 18^{\prime} 19^{\prime \prime} S \\
44^{\circ} 36^{\prime} 46^{\prime \prime} \mathrm{W}\end{array}$ \\
\hline LAd & Franco-arenosa & $\begin{array}{l}\text { Distante } 5 \text { km do município } \\
\text { de Rosário }\end{array}$ & $\begin{array}{l}21^{0} 17^{\prime} 05^{\prime \prime} \mathrm{S} \\
44^{\circ} 50^{\prime} 18^{\prime \prime} \mathrm{W}\end{array}$ \\
\hline LVAd & Muito argilosa & Viçosa & $\begin{array}{l}20^{\circ} 45^{\prime} 76^{\prime \prime} \mathrm{S} \\
42^{\circ} 52^{\prime} 49^{\prime \prime} \mathrm{W}\end{array}$ \\
\hline
\end{tabular}
Vermelho Amarelo Distrófico típico (Mélo, 2004)

A caracterização física incluiu a análise granulométrica, densidade dos solos, densidade das partículas, porosidade total, macro e microporosidade, condutividade hidráulica em meio saturado e retenção de água a -10 e $-1.500 \mathrm{kPa}$ (EMBRAPA, 1997; Ruiz, 2003) (Tabela 2).

Nas análises químicas do solo foram incluídas determinações de: $\mathrm{pH}$ em água; potássio e sódio trocáveis por fotometria de emissão de chama após extração com solução Mehlich-1; cálcio e magnésio trocáveis por espectrofotometria de absorção atômica, após extração com solução de $\mathrm{KCl} 1 \mathrm{~mol} \mathrm{~L}-1$; alumínio trocável por titulação após extração com solução $\mathrm{KCl} 1 \mathrm{~mol} \mathrm{~L}^{-1}$; fósforo disponível por colorimetria após extração com solução Melihch-1 e carbono orgânico pelo método Walkley-Black modificado (EMBRAPA, 1999) (Tabela 2).

As concentrações dos íons potássio, sódio, magnésio e cálcio solúveis na manipueira, foram 464,12;312,20; 43,98 e $19,64 \mathrm{mg} \mathrm{L}^{-1}$, respectivamente. Enquanto os teores de sólidos sedimentáveis e totais foram $50 \mathrm{~mL} \mathrm{~L}^{-1}$ e $11,9 \mathrm{mg} \mathrm{L}^{-1}$.

As colunas de percolação foram construídas usando-se segmentos de tubo de PVC de 7,5 cm de diâmetro interno e $40 \mathrm{~cm}$ de comprimento preenchidas até $30 \mathrm{~cm}$ com o material dos três solos. $\mathrm{Na}$ extremidade inferior das colunas colocou-se uma camada de $0,5 \mathrm{~cm}$ de areia, granulação $0,5-$ 1,0 mm, (Figura 1). Para se obter um perfil homogêneo, as colunas foram preenchidas em camadas de $3 \mathrm{~cm}$, em que 
Tabela 2. Caracterização física e química de amostras dos três solos utilizados, antes de ser aplicada a água residuária de mandioca

\begin{tabular}{|c|c|c|c|}
\hline Característica & $\mathrm{RQ}_{0} \mathbf{1}^{1}$ & LAd1 & LVAd1 \\
\hline Areia grossa (g kg-1) & 660 & 350 & 190 \\
\hline Areia fina $\left(\mathrm{g} \mathrm{kg}^{-1}\right)$ & 250 & 390 & 70 \\
\hline Silte $\left(\mathrm{g} \mathrm{kg}^{-1}\right)$ & 20 & 90 & 40 \\
\hline Argila $\left(\mathrm{g} \mathrm{kg}^{-1}\right)$ & 70 & 170 & 700 \\
\hline Densidade do solo $\left(\mathrm{kg} \mathrm{dm}^{-3}\right)$ & 1,47 & 1,26 & 1,03 \\
\hline Densidade das partículas $\left(\mathrm{kg} \mathrm{dm}^{-3}\right)$ & 2,57 & 2,53 & 2,52 \\
\hline Porosidade total ( $\left.\mathrm{dm}^{3} \mathrm{dm}^{-3}\right)$ & 0,43 & 0,50 & 0,60 \\
\hline Macroporosidade $\left(\mathrm{dm}^{3} \mathrm{dm}^{-3}\right)$ & 0,22 & 0,16 & 0,20 \\
\hline Microporosidade $\left(\mathrm{dm}^{3} \mathrm{dm}^{-3}\right)$ & 0,21 & 0,34 & 0,40 \\
\hline Condutividade hidráulica $\left(\mathrm{cm} \mathrm{h}^{-1}\right)$ & 68,1 & 7,2 & 37,8 \\
\hline pH em água $(1: 2,5)$ & 5,07 & 5,37 & 4,84 \\
\hline Potássio $\left(\mathrm{cmol}_{\mathrm{c}} \mathrm{kg}^{-1}\right)$ & 0,07 & 0,11 & 0,07 \\
\hline Sódio $\left(\mathrm{cmol}_{\mathrm{c}} \mathrm{kg}^{-1}\right)$ & 0,05 & 0,10 & 0,09 \\
\hline Cálcio $\left(\mathrm{cmol}_{\mathrm{c}} \mathrm{kg}^{-1}\right)$ & 0,57 & 1,21 & 0,67 \\
\hline Magnésio $\left(\mathrm{cmol}_{\mathrm{c}} \mathrm{kg}^{-1}\right)$ & 0,14 & 0,33 & 0,24 \\
\hline Alumínio $\left(\mathrm{cmol}_{\mathrm{c}} \mathrm{kg}^{-1}\right)$ & 6,2 & 3,6 & 3,1 \\
\hline Carbono orgânico (g kg-1) & 7,4 & 6,3 & 13,1 \\
\hline
\end{tabular}

RQo - Neossolo Quartzarênico ortico
Vermelho Amarelo Distrófico típico

cada camada adicionada era misturada à anterior, empregando-se um misturador construído com pequeno disco de madeira de aproximadamente $7 \mathrm{~cm}$ de diâmetro, no qual foram cravados vários pregos e, posteriormente, fixado a uma haste cilíndrica permitindo, assim, o movimento rotacional, com as mãos, ao se misturar uma camada com a subseqüente.

Para obtenção de colunas de mesma densidade para cada material de solo, este era previamente pesado e acomodado nas colunas, até atingir $30 \mathrm{~cm}$ de espessura, por meio de toques leves com um martelo de borracha; para isto, a superfície do solo foi protegida com discos de lã de vidro, para prevenir distúrbios durante a conexão ao frasco de Mariotte contendo a manipueira.

O volume de poros das colunas de solo foi calculado empregando-se a equação

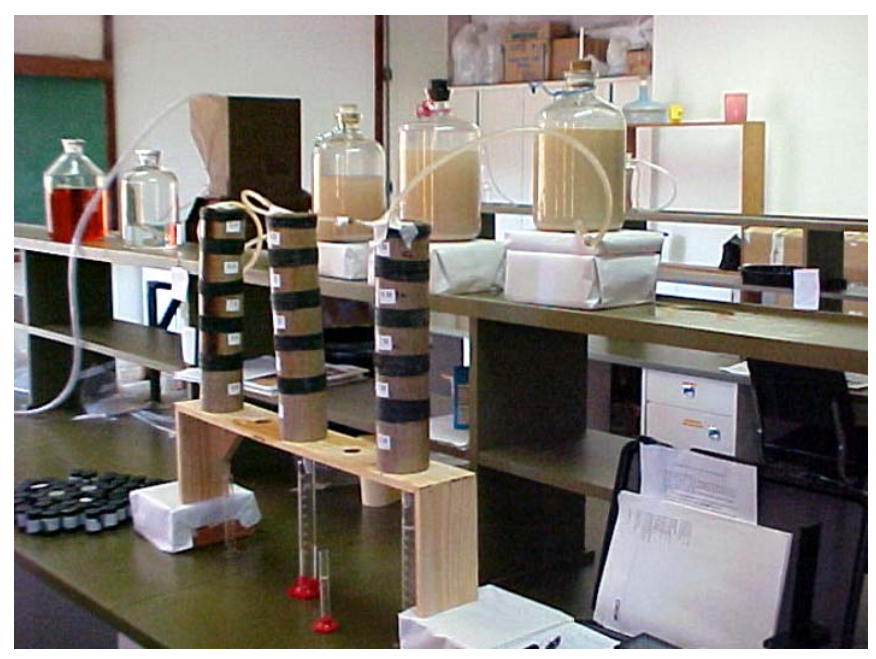

Figura 1. Vista geral do ensaio de deslocamento miscível

$$
\mathrm{V}_{\mathrm{p}}=\alpha \mathrm{V}=\pi \mathrm{r}^{2} \mathrm{~h}\left(1-\frac{\rho_{\mathrm{s}}}{\rho_{\mathrm{p}}}\right)
$$

em que:

$$
\begin{aligned}
& \mathrm{V}_{\mathrm{p}} \text { - volume de poros, } \mathrm{cm}^{3} \\
& \mathrm{~V}-\text { volume da coluna de solo, } \mathrm{cm}^{3} \\
& \alpha-\text { porosidade, } \mathrm{cm}^{3} \mathrm{~cm}^{-3} \\
& \mathrm{r} \text { - raio interno da coluna, } \mathrm{cm} \\
& \mathrm{h} \text { - espessura da coluna de solo, } \mathrm{cm} \\
& \rho_{\mathrm{s}} \text { - massa específica do solo, } \mathrm{g} \mathrm{\textrm {cm } ^ { - 3 }} \\
& \rho_{\mathrm{p}}-\text { massa específica das partículas do solo, } \mathrm{g} \mathrm{cm}^{-3}
\end{aligned}
$$

Foram utilizados dois frascos de Mariotte, sendo um contendo água destilada e o outro a manipueira. Inicialmente, interligou-se à coluna de solo ao frasco com água destilada até passar aproximadamente dois volumes de poros, mantendo-se uma lâmina de $4 \mathrm{~cm}$ acima da superfície; a seguir, desconectou-se o frasco contendo a água destilada e, após completa infiltração da lâmina de água, interligou-se o frasco de Mariotte contendo a manipueira mantendo-se, também, a lâmina de $4 \mathrm{~cm}$ sobre a superfície.

Foram aplicados três volumes de poro da manipueira recolhendo-se continuamente 21 alíquotas de 0,15 volume de poros do efluente, as quais foram acondicionadas em recipientes plásticos, com tampa, e congeladas para análises posteriores. Conhecendo-se as concentrações de potássio, cálcio, magnésio e sódio no efluente $(\mathrm{C})$, calcularam-se as concentrações relativas $(\mathrm{C} / \mathrm{Co})$ para cada íon, sendo Co a concentração dos íons na manipueira.

O fluxo foi calculado empregando-se

$$
\mathrm{q}=\frac{\mathrm{V}_{\mathrm{e}}}{\mathrm{At}}=\frac{\mathrm{Q}}{\mathrm{A}}
$$

em que:

$$
\begin{aligned}
& \mathrm{q} \text { - fluxo, } \mathrm{cm} \mathrm{min}^{-1} \\
& \mathrm{Ve} \text { - Volume de efluente, } \mathrm{cm}^{3} \\
& \mathrm{~A} \text { - área da seção transversal da coluna, } \mathrm{cm}^{2} \\
& \mathrm{t} \text { - intervalo de tempo para coletar o volume Ve, } \mathrm{h} \\
& \mathrm{Q} \text { - vazão, } \mathrm{cm}^{3} \mathrm{~h}^{-1}
\end{aligned}
$$

A velocidade média de percolação da manipueira, $\mathrm{v}_{\mathrm{m}}(\mathrm{cm}$ $\mathrm{h}^{-1}$ ), foi calculada para cada solo, pela relação

$$
\mathrm{v}_{\mathrm{m}}=\frac{\mathrm{q}}{\alpha}
$$

em que $\alpha$ é a porosidade, $\mathrm{cm}^{3} \mathrm{~cm}^{-3}$

De posse das concentrações relativas e dos respectivos números de volume de poros, obtiveram-se as curvas experimentais de efluente para cada íon e solo.

Os fatores de retardamento e os coeficientes dispersivosdifusivos foram calculados utilizando-se o programa computacional Disp 1.1; este programa ajusta as soluções matemáticas da equação diferencial de transporte de solutos no solo, equação 4, aos dados experimentais de concentrações relativas com base na menor soma dos mínimos quadrados dos resíduos, Rs, (Eq. 5) (Borges Jr \& Ferreira, 2003). 


$$
\mathrm{R} \frac{\partial \mathrm{C}}{\partial \mathrm{t}}=\mathrm{D} \frac{\partial^{2} \mathrm{C}}{\partial \mathrm{x}^{2}}-\mathrm{v} \frac{\partial \mathrm{C}}{\partial \mathrm{x}}
$$

em que:

$$
\begin{aligned}
& \mathrm{R} \text { - fator de retardamento, adimensional } \\
& \mathrm{C} \text { - concentração do soluto, } \mathrm{g} \mathrm{L}^{-1} \\
& \mathrm{t} \text { - tempo, } \mathrm{h} \\
& \mathrm{X} \text { - distância à superfície do solo, } \mathrm{cm} \\
& \mathrm{D} \text { - coeficiente dispersivo-difusivo, } \mathrm{cm}^{2} \mathrm{~h}^{-1} \\
& \mathrm{v} \text { - velocidade média de escoamento, } \mathrm{cm} \mathrm{h}^{-1} \text {. }
\end{aligned}
$$

$$
\mathrm{R}_{\mathrm{S}}=\sum_{\mathrm{i}=1}^{\mathrm{n}}\left[\left(\frac{\mathrm{C}}{\mathrm{C}_{0}}\right)(\mathrm{L}, \mathrm{p})-\left(\frac{\mathrm{C}}{\mathrm{C}_{0}}\right)_{\mathrm{e}}(\mathrm{L}, \mathrm{p})\right]^{2}
$$

onde, além dos parâmetros já mencionados, tem-se:

$\mathrm{n}$ - número de observações

$\mathrm{C} / \mathrm{C} 0$ - concentrações relativas experimentais

$\mathrm{C} / \mathrm{C} 0 \mathrm{e}$ - concentrações relativas estimadas

$\mathrm{L}$ - espessura da coluna de solo, cm

$\mathrm{p}$ - número de volume de poros

Os dados relativos à coluna e ao escoamento, como comprimento, fluxo, concentração do soluto, porosidade total, número de volume de poros e concentração relativa, constituem parâmetros de entrada no Disp, enquanto o coeficiente dispersivo-difusivo (D), fator de retardamento (R) número de Peclet $(\mathrm{P})$ e as curvas de efluente e concentração residente são dados de saída.

\section{RESULTADOS E DISCUSSÃO}

As características volume de poros, fluxo e velocidade média de avanço da solução nas colunas preenchidas com os três solos, encontram-se na Tabela 3.

Tabela 3. Volume de poros, fluxo e velocidade de escoamento da manipueira nas colunas preenchidas com as classes de solo

\begin{tabular}{lccc}
\hline \multirow{1}{*}{ Propriedades Físicas } & \multicolumn{3}{c}{ Classes de Solo } \\
\cline { 2 - 4 } & RQo & LAd & LVAd \\
Volume de Poros $\left(\mathrm{cm}^{3}\right)$ & 570 & 663 & 782 \\
Fluxo $\left(\mathrm{cm} \mathrm{h}^{-1}\right)$ & 10,14 & 9,26 & 1,79 \\
Velocidade de Avanço $\left(\mathrm{cm} \mathrm{h}^{-1}\right)$ & 23,58 & 18,52 & 3,03 \\
\hline
\end{tabular}

1R0o - Neossolo Ouartzarênico órtico espódico; LAd - Latossolo Amarelo Distrófico típico; LVAd - Latossolo Vermelho Amarelo Distrófico típico

A análise dos dados apresentados na Tabela 3 mostra coerência com as características de densidade, porosidade e volume de poros apresentados na Tabela 2, ou seja, fluxo e velocidade de escoamento em meio saturado decrescem no sentido do RQo para LVAd. Embora possua porosidade total maior, o Latossolo apresenta menor porcentagem de macroporos, resultando em menor velocidade de escoamento em meio saturado. Outra razão para a acentuada redução na velocidade de escoamento, no Latossolo, pode ter sido a obstrução de poros por materiais orgânicos em suspensão na manipueira, uma vez que materiais de textura mais grossa ficaram retidos na camada superficial do solo montado na coluna, sendo o material de textura mais fina penetrado na

\begin{tabular}{|c|c|c|c|c|c|c|c|c|}
\hline \multirow[t]{2}{*}{ Solo ${ }^{1}$} & \multicolumn{4}{|c|}{$\begin{array}{l}\text { Coeficiente Dispersivo-Difusivo } \\
\qquad \mathrm{cm}^{2} \mathrm{~h}^{-1}\end{array}$} & \multicolumn{4}{|c|}{ Fator de Retardamento } \\
\hline & $\mathrm{K}^{+}$ & $\mathrm{Ca}^{2+}$ & $\mathrm{Mg}^{2+}$ & $\mathrm{Na}^{+}$ & $\mathbf{K}^{+}$ & $\mathrm{Ca}^{2+}$ & $\mathrm{Mg}^{2+}$ & $\mathrm{Na}^{+}$ \\
\hline RQo & 125,0 & 98,2 & 99,3 & 62,7 & 1,75 & 1,18 & 1,69 & 1,83 \\
\hline LAd & 30,8 & 35,1 & 35,1 & 42,1 & 1,52 & 1,28 & 2,00 & 1,58 \\
\hline LVAd & 6,1 & 3,1 & 8,6 & 6,7 & 2,39 & 2,00 & 2,37 & 2,36 \\
\hline
\end{tabular}
coluna de solo e, posteriormente, obstruído os poros.

$\mathrm{Na}$ Tabela 4 e nas Figuras 2 a 4, tem-se os resultados obtidos para coeficiente dispersivo-difusivo e o fator de retardamento para os cátions estudados.

Tabela 4. Coeficientes dispersivo-difusivos e fatores de retardamento para os íons potássio, cálcio, magnésio e sódio para os três solos estudados

Segundo Nielsen \& Biggar (1962), as curvas de efluente são importantes ao se estudar o transporte de solutos no perfil do solo, durante uma percolação. O número de volume de poros correspondente à concentração relativa 0,5 é uma primeira indicação, no sentido da existência ou não, de interações soluto-solo. Quando o valor correspondente a 0,5, a concentração relativa é 1,0 volume de poros e, o soluto não está interagindo com a fração coloidal do solo; por outro lado, quando o valor é maior que 1,0 , isto é, a curva de efluente se apresenta deslocada para a direita, significa que, ao escoar através do perfil do solo, parte do soluto é adsorvida, resultando um fator de retardamento maior que a unidade; portanto, quanto maior for o fator de retardamento, maior será a interação soluto-solo.

Para uma mesma velocidade média de escoamento de uma solução, valores mais elevados do coeficiente dispersivo-difusivo correspondem a uma declividade menor da curva de efluente, em virtude da maior mistura na interface entre os fluidos deslocado e deslocador.

A Tabela 4 mostra, com base nos valores dos fatores de retardamento, a crescente interação dos íons analisados com a fração coloidal dos solos no sentido do RQo para o LVAd, exceto para o cálcio no LVAd, cujo valor foi, inexplicavelmente, mais alto que aqueles encontrados para os solos RQo e LAd.

$\mathrm{O}$ fator de retardamento, por ser uma característica que retrata a capacidade do solo em reter os solutos à medida que o fluxo de massa avança, depende das interações entre as fases líquida e sólida que ocorrem durante a percolação. Os menores valores de $\mathrm{R}$ foram encontrados para os íons magnésio, no RQo, sódio e potássio para LAd e cálcio para LVAd.

Os dados obtidos demonstram que nas colunas de LVAd os valores de $\mathrm{R}$ foram, em geral, maiores, refletindo a maior capacidade de adsorção deste solo; enfim, nas colunas dos outros dois solos os maiores fatores de retardamento foram para o íon sódio, no RQo, e para os íons cálcio e magnésio, no LAd.

O LVAd, de textura muito argilosa, possui capacidade de adsorção de cátions mais elevada que os outros solos e, conseqüentemente, os maiores valores de $\mathrm{R}$ para os íons potássio, 


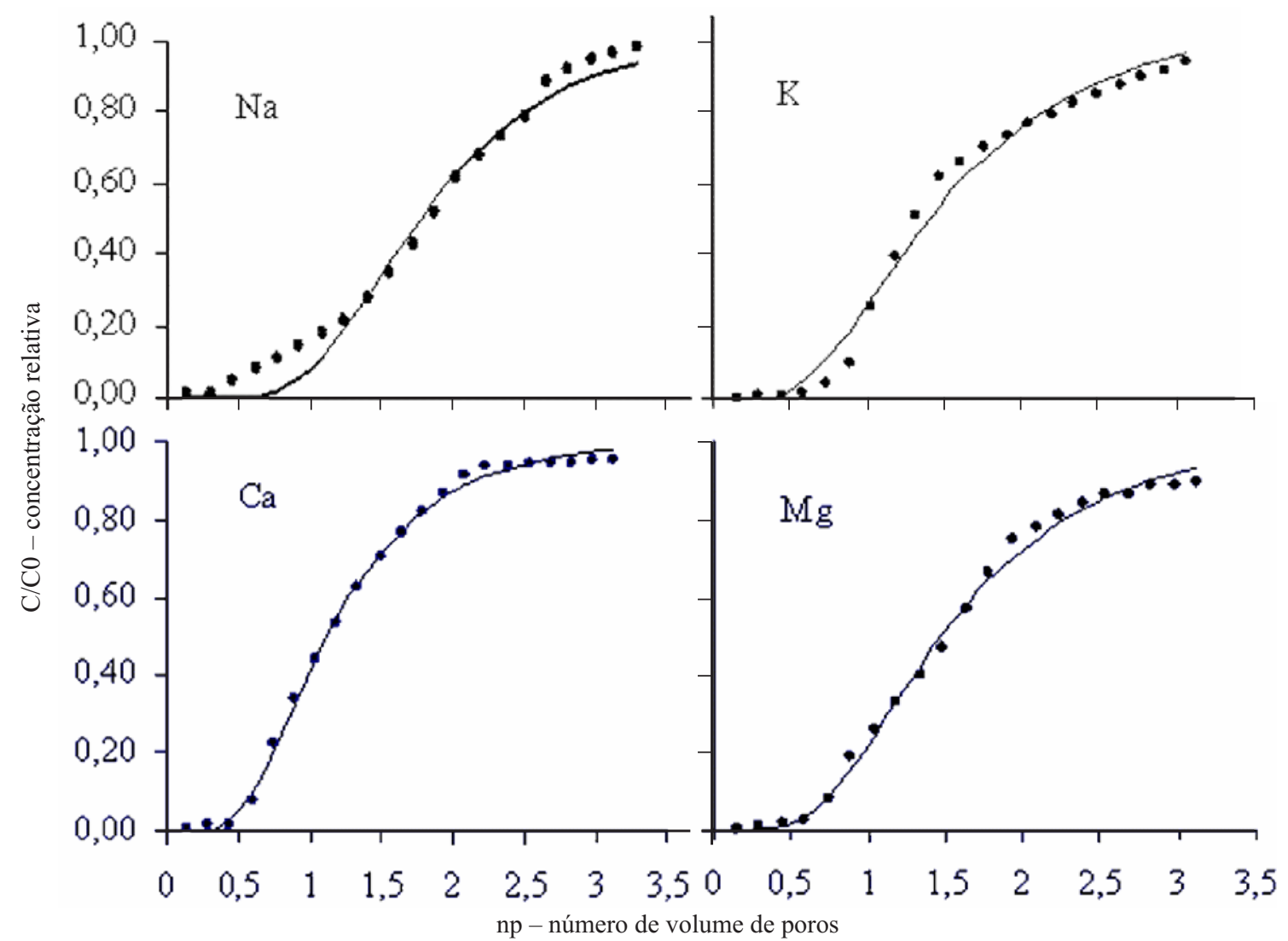

Figuras 2. Curvas de efluente para o sódio, potássio, cálcio e magnésio, ajustadas aos dados experimentais utilizando-se o programa computacional DISP, para o solo de textura arenosa (RQo)

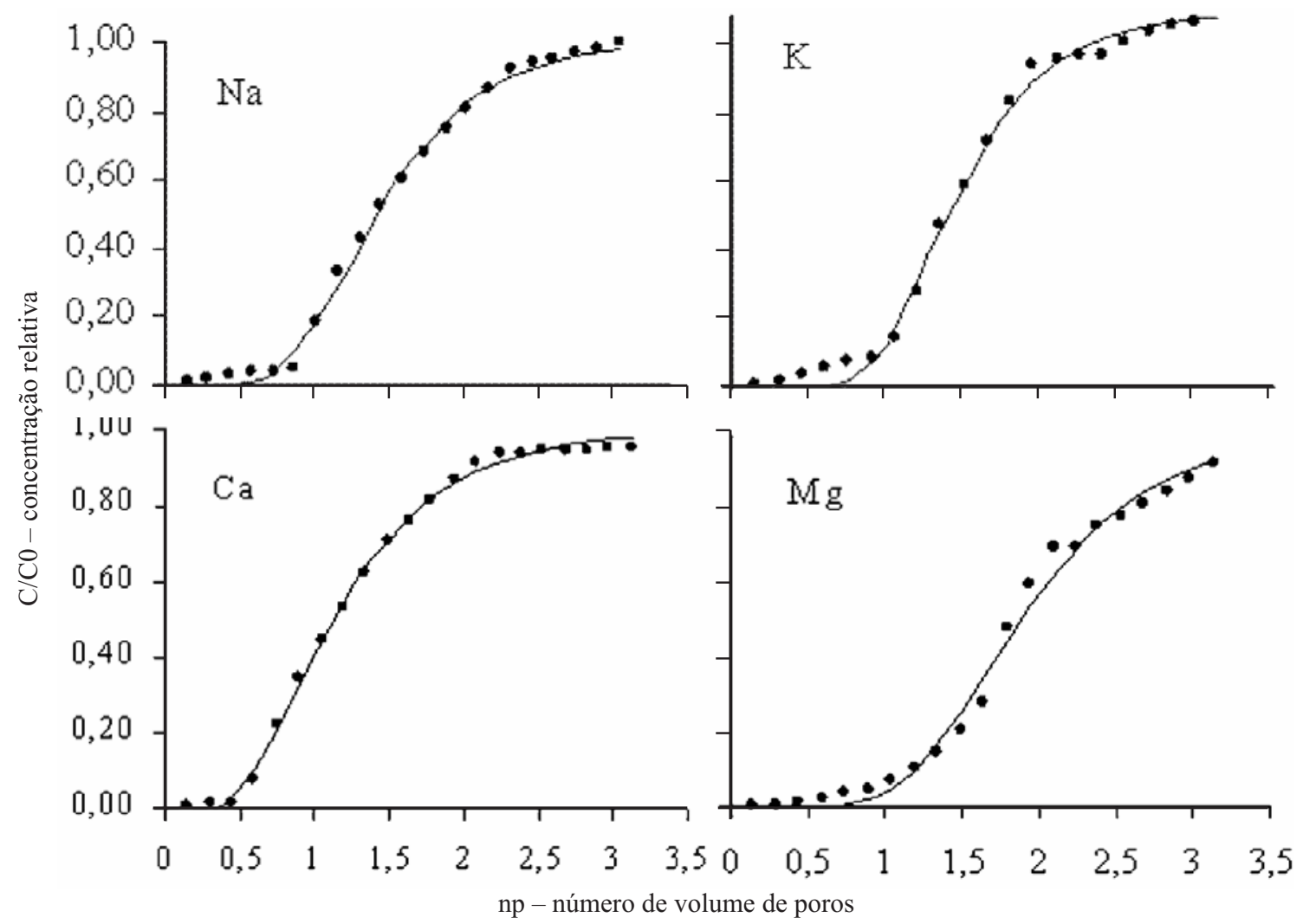

Figuras 3. Curvas de efluente para o sódio, potássio, cálcio e magnésio, ajustadas aos dados experimentais utilizando-se o programa computacional DISP, para o solo de textura média (LAd) 


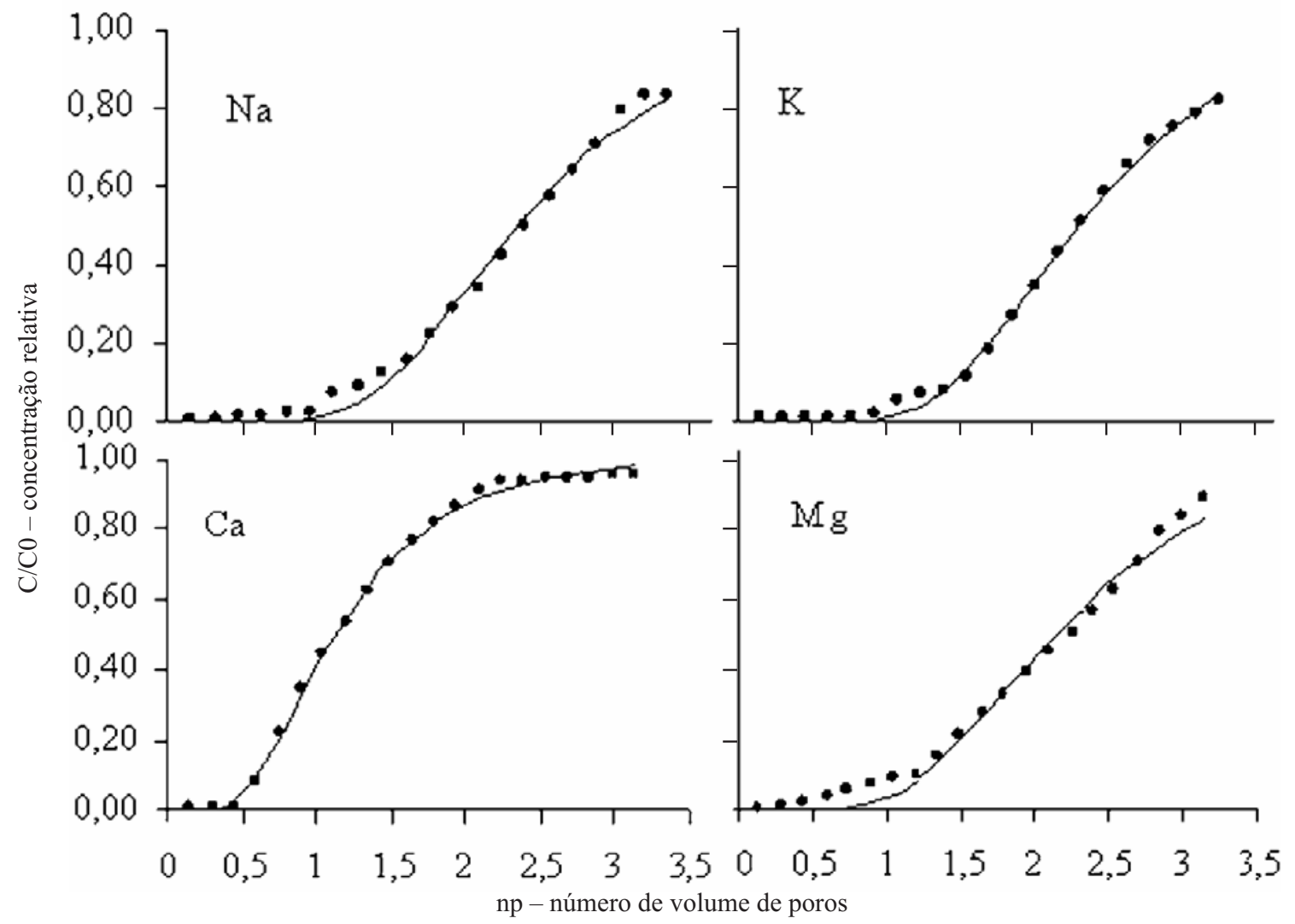

Figuras 4. Curvas de efluente para o sódio, potássio, cálcio e magnésio, ajustadas aos dados experimentais utilizando-se o programa computacional DISP, para o solo de textura argilosa (LVAd)

magnésio e sódio,que são os cátions presentes na manipueira em maiores concentrações. Esta maior capacidade adsortiva já era esperada, uma vez que o LVAd contém maiores teores de argila e de matéria orgânica, resultando em maior defasagem entre o avanço do solvente e o avanço do soluto no solo. Resultados semelhantes foram encontrados por Alcântara \& Camargo (2001) para um Latossolo Vermelho eutroférrico do Estado de São Paulo.

Merece destaque a ocorrência do valor do fator de retardamento para o cálcio, no LVAd por ser, inexplicavelmente, quase o dobro, quando comparado com os valores dos outros dois solos (Tabela 4). Por outro lado, os valores de R menores para o RQo estão em consonância com a menor CTC e maior velocidade de avanço, proporcionando menor tempo de interação íon-colóide, porém para os íons sódio e potássio os valores de $\mathrm{R}$ foram relativamente baixos, fato que pode ser devido à maior presença desses íons na manipueira e/ou ao material sólido nela presente ocasionando, assim, obstruções de poros do solo, resultando numa interação ioncolóide maior.

Os referidos resultados estão evidenciados também pelo maior deslocamento das curvas de efluente para a direita, nas Figuras 2 a 4, para esses íons, cujos resultados se assemelham aos encontrados por Rao et al. (1980) e sugerem que, quanto maior o deslocamento da curva de efluente para a direita, maior também é a adsorção na superfície dos colóides, a qual está relacionada com a energia de adsorção do íon.

Ressalta-se que, ao suprir as necessidades nutricionais de determinada cultura com a aplicação de fertirrigação usando água residuária como fontes de nutrientes devem, também, nos preocupar-mos com a possibilidade de contaminação das águas subterrâneas pela movimentação dos íons, tendo-se em conta que um fator maior de retardamento significa menor mobilidade do íon no solo e, conseqüentemente, menor probabilidade de contaminação de águas freáticas. Neste sentido, ensaios de deslocamento miscível podem ser úteis ao manejo da fertilização, no sentido de minimizar as perdas de nutrientes por percolação profunda, ao serem aplicadas tais águas e o comportamento dos íons nos solos estudados alerta para este fato. Outro dado importante ao se determinar a lâmina de água residuária a aplicar por irrigação, é a concentração do íon presente em maior concentração; no caso da manipueira, o potássio foi o cátion considerado.

Valores mais elevados dos coeficientes de dispersão-difusão estão associados a menores inclinações das curvas de efluente e, conseqüentemente, ao alargamento da faixa de mistura entre as soluções deslocadora e deslocada no perfil do solo, tornando os acréscimos na concentração relativa $(\mathrm{C} /$ Co) baixos para acréscimos no número de volume de poros (Nielsen \& Biggar, 1962; Alvarez et al., 1985).

Para todos os íons estudados, os valores mais altos dos coeficientes de dispersão-difusão foram para o solo de textura arenosa (Tabela 4). Quando se comparou o LAd com o LVAd, texturas média e argilosa, respectivamente, verificaram-se maiores valores de D para o LAd, cuja velocidade de avanço foi cerca de seis vezes maior para um mesmo gradiente hidráulico. 


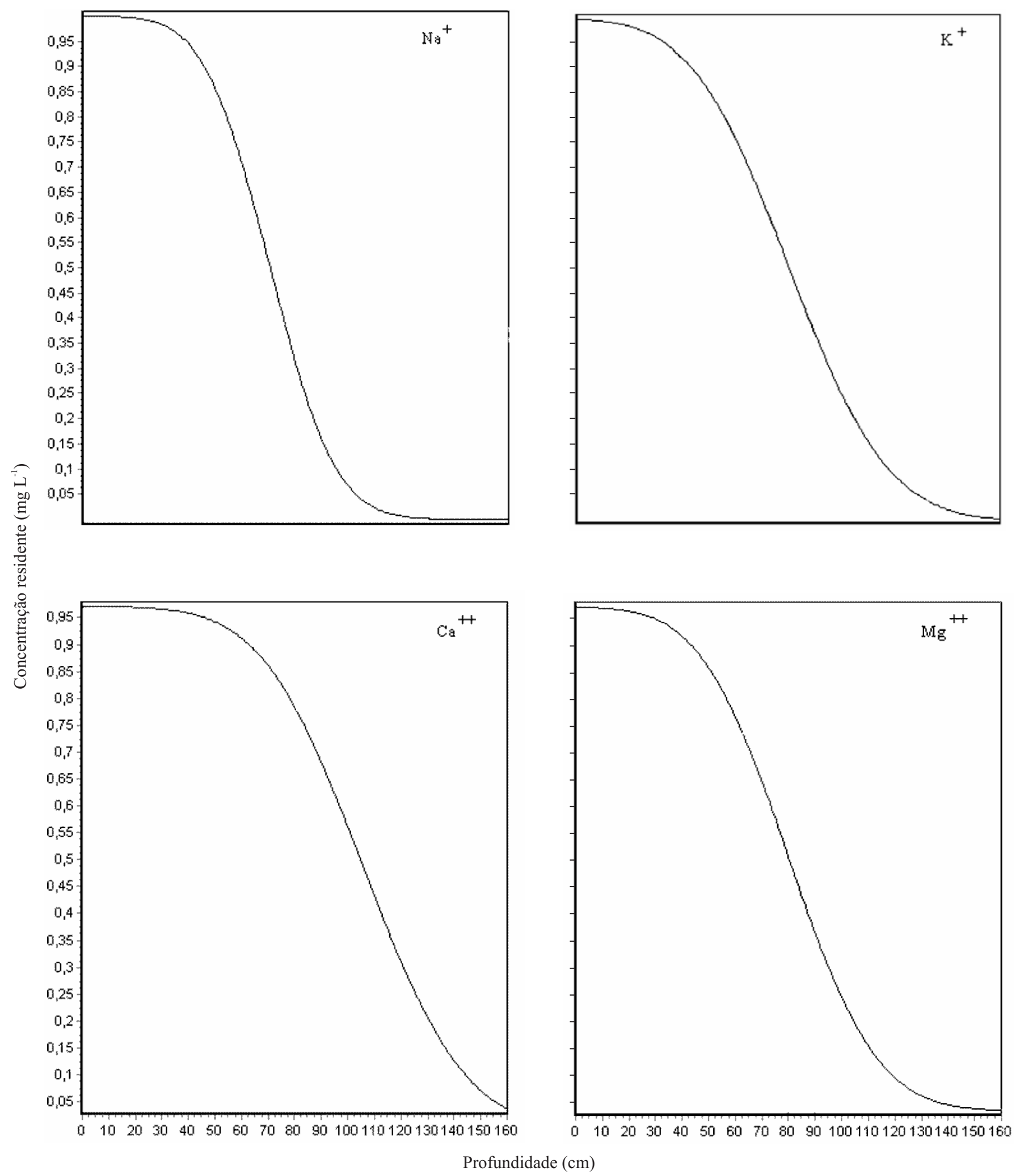

Figura 5. Concentração residente $\left(\mathrm{mg} \mathrm{L}^{-1}\right)$ relativa aos íons de sódio, potássio, cálcio e magnésio presentes na água residuária da indústria de mandioca, em perfis de $160 \mathrm{~cm}$ dos solos de textura arenosa 


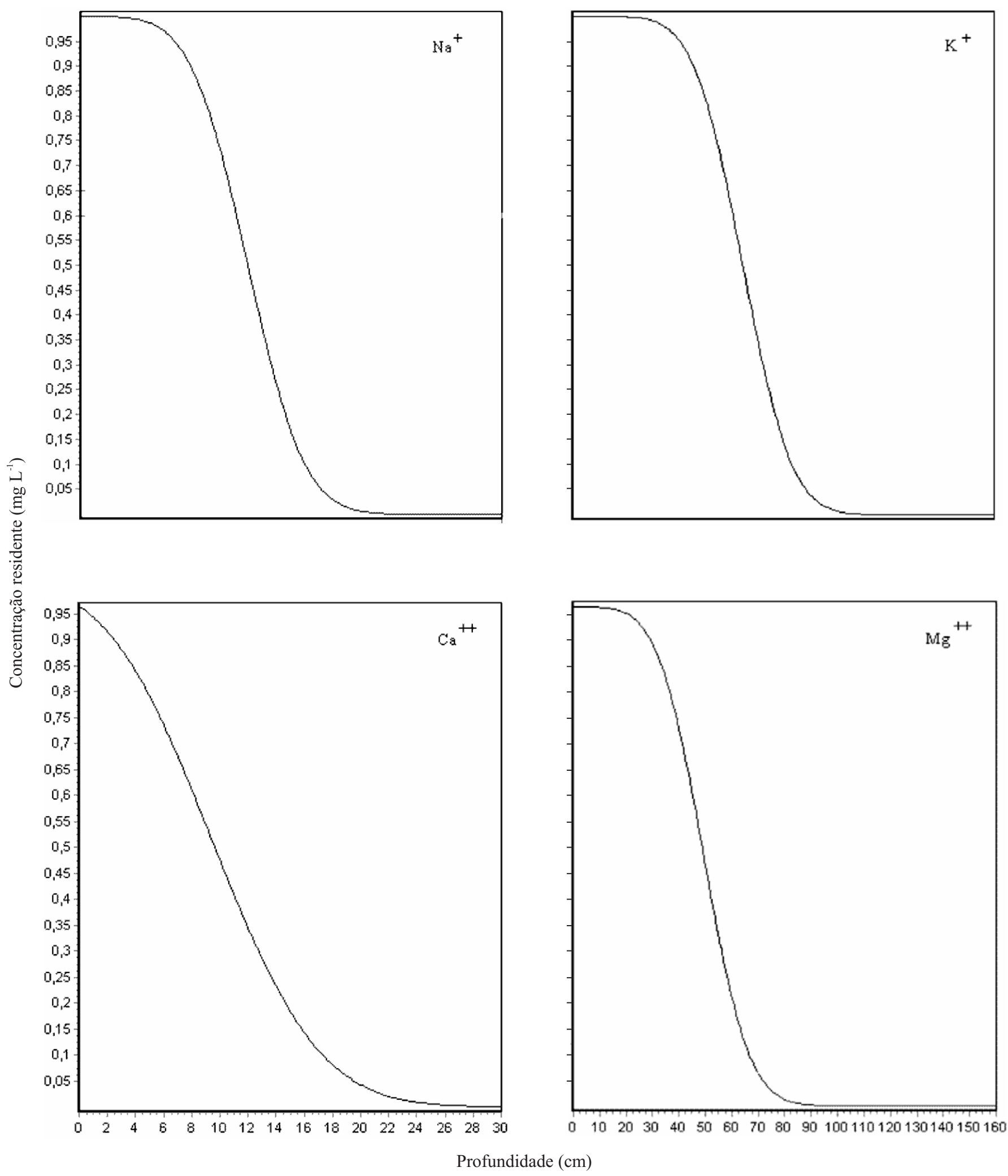

Figura 6. Concentração residente $\left(\mathrm{mg} \mathrm{L}^{-1}\right)$ relativa aos íons de sódio, potássio, cálcio e magnésio presentes na água residuária da indústria de mandioca, em perfis de $160 \mathrm{~cm}$ dos solos de textura média 

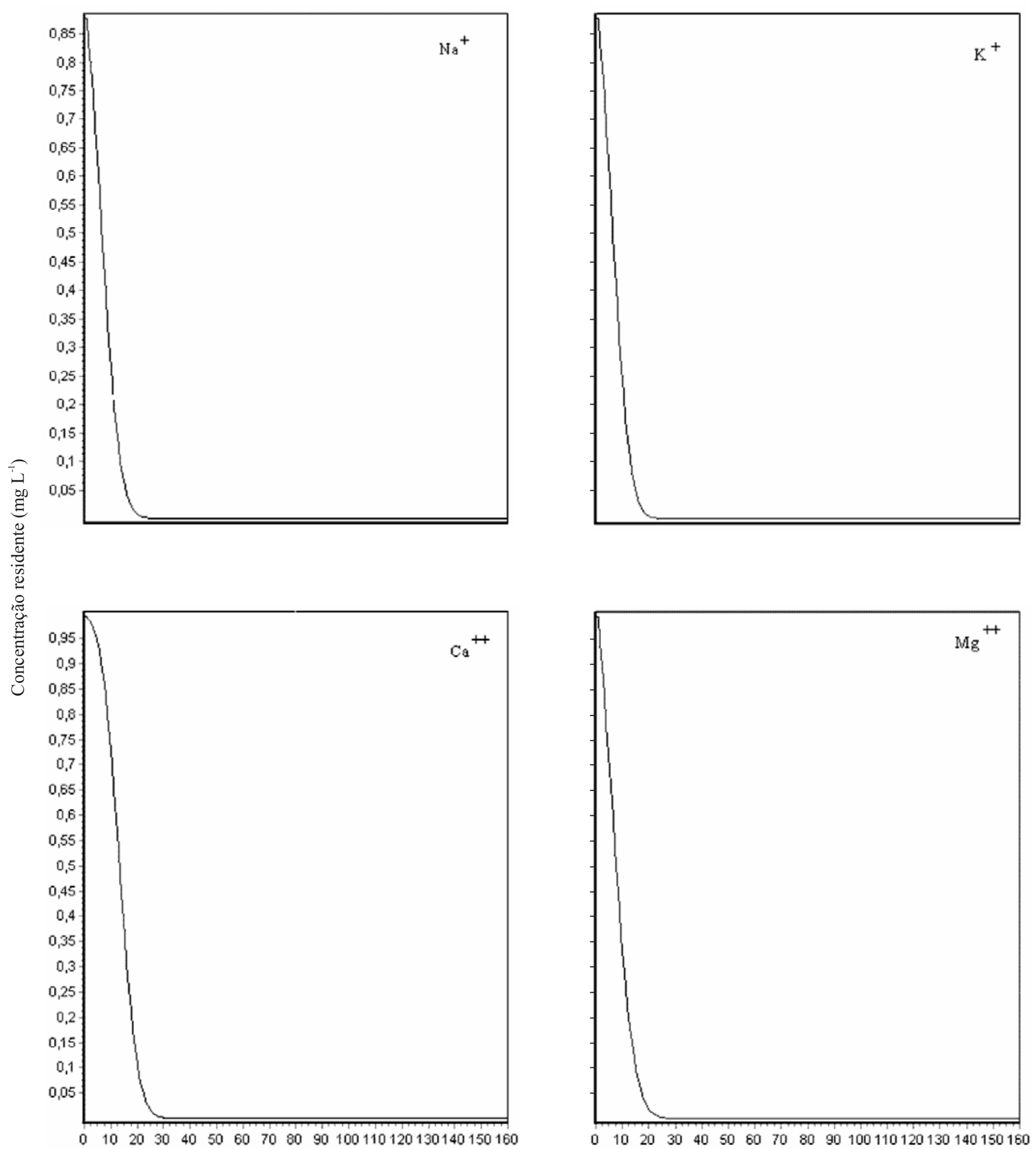

Profundidade $(\mathrm{cm})$

Figura 7. Concentração residente $\left(\mathrm{mg} \mathrm{L}^{-1}\right)$ relativa aos íons de sódio, potássio, cálcio e magnésio presentes na água residuária da indústria de mandioca, em perfis de $160 \mathrm{~cm}$ dos solos de textura argilosa 
Matos (1995) verificou que a propriedade física que melhor explicou a variação dos coeficientes de dispersão-difusão para zinco, cádmio, cobre e chumbo, foi a velocidade de avanço da solução através da seção de escoamento, formada por macroporos. O mesmo autor ressaltou a importância da macroporosidade em estudos de dispersão-difusão de metais pesados no solo.

Enquanto a concentração do soluto no fluxo corresponde à massa de soluto por unidade de volume da solução que passa através de uma seção transversal durante um intervalo elementar de tempo, a concentração residente é a concentração média do soluto na solução do solo naquela seção; salienta-se, então, que a concentração no efluente é a concentração no fluxo na seção transversal de saída (Parker \& van Genuchten, 1984).

As concentrações residentes dos íons contidos na água residuária da indústria de fecularia $\left(\mathrm{mg} \mathrm{L}^{-1}\right)$ relativas aos íons de sódio, potássio, cálcio e magnésio, em colunas de $160 \mathrm{~cm}$ dos solos de textura argilosa, média e arenosa., simuladas com o auxílio do programa computacional DISP, estão apresentadas nas Figuras 5, 6 e 7, na qual se tem, também, o avanço diferenciado dos íons no período de simulação de cinco horas, para os três solos.

Por meio das curvas de concentração residente verificase que os íons avançaram mais na coluna de solo de textura arenosa em relação aos de textura média e argilosa cujos fatores de retardamento são, em geral, maiores (Tabela 4). Esses aspectos alertam para os perigos de contaminação de lençol freático ao se aplicar a manipueira em solos de baixa capacidade de adsorção, ou seja, baixo fator de retardamento, como é o caso do solo arenoso.

\section{CONCLUSÕES}

1. Os valores mais elevados dos fatores de retardamento ocorreram para o solo argiloso, indicando maior retenção dos cátions potássio, sódio, cálcio e magnésio neste solo, sendo, portanto, influenciadas pela textura do solo.

2. Os valores dos coeficientes dispersivos-difusivos decresceram no sentido do solo arenoso para o argiloso.

3. A simulação para um período de aplicação da manipueira de cinco horas mostrou pequeno avanço dos íons na coluna do solo argiloso, em comparação com os solos de textura média e arenosa, alertando, para os perigos de contaminação de águas subterrâneas ao se aplicar a manipueira em tais solos.

\section{LITERATURA CITADA}

Alcântara, M. A. K.; Camargo, A. Fator de retardamento e coeficiente de dispersão-difusão para o crômio (III) em solos muito intemperizados, influenciados pelo $\mathrm{pH}$, textura e matéria orgânica. Revista Brasileira de Ciência do Solo, Viçosa, v.25, p. 209-216. 2001.
Alvarez, J.; Herguedas, A.; Atienza, J.; Bolado, S. Modelización numérica y estimación de parámetros para la descripción del transporte de solutos en columnas de suelo en laboratorio. Madrid: Instituto Nacional de Investigación y Tecnologia Agraria y Alimentaria, 1985. 69p.

APHA - American Public Health Association. Standard methods for the examination of water and wastewater. 19.ed. Washington: APHA, 1995. 874p.

Borges Jr., J. C. F.; Ferreira, P. A. Programa computacional aplicável ao cálculo dos parâmetros de transporte de solutos no solo em deslocamento de fluidos miscíveis. Viçosa: DEA/UFV. 2003. Programa em fase de testes.

EMBRAPA - Empresa Brasileira de Pesquisa Agropecuária. Manual de análises de solo. Rio de Janeiro: EMBRAPA, 1997. 212p.

EMBRAPA - Empresa Brasileira de Pesquisa Agropecuária. Manual de análises químicas de solos, plantas e fertilizantes. Brasília: EMBRAPA, 1999. 370p.

Ferreira, P. A. Manejo de água planta em solos salinos. Viçosa: UFV, 2003. 111p. Apostila de aula do curso de pós-graduação

Matos, A. T. Fatores de retardamento e coeficiente de dispersão-difusão do zinco, cádmio, cobre e chumbo em solos do Município de Viçosa, MG, Viçosa:UFV, 1995. 110p. Tese Doutorado

Matos, A. T.; Brasil, M. S.; Fonseca, S. P. P. Aproveitamento de efluentes líquidos domésticos e agroindustriais na agricultura. In: Encontro de Preservação de Mananciais da Zona da Mata Mineira, Viçosa, 2, 2003, Anais..., Viçosa: ABES, 2003. p.25-79.

Matos, A. T.; Sediyama, M. A. N.; Vidigal, S. M. Características químicas, físicas e microbiológicas do solo influenciadas pela aplicação de compostos orgânicos ou dejeto líquido de suínos. In: Seminário Mineiro Sobre Manejo e Utilização de Dejetos de Suínos, 1, 1995, Ponte Nova. Anais..., Viçosa: EPAMIG, 1995. p.33-34.

Nielsen, D. R.; Biggar, J. W. Miscible displacemente: III Theoretical considerations. Soil Sciense Society of American Proceeding. Madison, v.26, p.216-221, 1962.

Parker, J. C.; van Genuchten, M. T. Determining transport parameters from laboratory and field tracer experiments. Virginia: Agriculture Experimental Station, 1984. 89p.

Ponte, J. J. Cartilha da manipueira: uso do composto como insumo agrícola. Fortaleza: Secretaria de Ciência e Tecnologia, 1999. 53p.

Rao, P. S. C.; Rolston, D. E.; Jessup, R. E.; Davidson, J. M. Solute transport in aggregated porous media: theoretical and experimental evaluation. Soil Sciense Society of American Journal, Madison, v.44, p.1139-1146, 1980.

Ruiz, H. A. Métodos de análises físicas do solo. Viçosa: UFV, 2003. 22p. Apostila

Rump, H. H.; Krist, H. Laboratory manual for the examination of water, wastewater, and soil. Weinheim: VCH, 1992. 190p.

Vilas Boas, E. V. B.; Lima, L. C. O.; Bressan, M. C.; Barcelos, M. F. P.; Pereira, R. G. F. A. Manejo de resíduos da agroindústria. Lavras: UFLA/FAEPE, 2001, p.81-95. 